\title{
Perspective Summary of Brief Report on Thyroid Disease of Post Glaciations Quaternary Is Endocrinology of Ecology System in Centre Marc Sankale Setting in Dakar
}

\author{
El Hassane Sidibe ${ }^{1, ~ *}$, Therese Moreira-Diop², Jean-Francois Bach ${ }^{3}$, Baye Assane Diagne ${ }^{2}$, \\ Francis Klotz ${ }^{4}$ \\ ${ }^{1}$ Centre de Clinique Medicale Marc Sankale [Hopital Abass N’Dao] Fellow du Collège de Médecine de Paris [Inside Salk.edu] RCL \\ Guillemin Chair, Dakar, Senegal \\ ${ }^{2}$ Faculte de Medecine Pharmacie \& Odontologie [UCAD], Dakar, Senegal \\ ${ }^{3}$ Laboratoire d'Immunologie Clinique [Hopital Necker Enfants Malades], Paris, France \\ ${ }^{4}$ Hopital Val de Grace [Instruction des Armees], Paris, France
}

Email address:

ehsidibe2016@gmail.com (El H. Sidibe)

*Corresponding author

\section{To cite this article:}

El Hassane Sidibe, Therese Moreira-Diop, Jean-Francois Bach, Baye Assane Diagne, Francis Klotz. Perspective Summary of Brief Report on Thyroid Disease of Post Glaciations Quaternary Is Endocrinology of Ecology System in Centre Marc Sankale Setting in Dakar. Clinical Medicine Research. Vol. 9, No. 3, 2020, pp. 59-64. doi: 10.11648/j.cmr.20200903.13

Received: April 6, 2020; Accepted: May 8, 2020; Published: June 8, 2020

\begin{abstract}
Reflexions about immunoradiometric Tsh and Trh test during on Optimal thyroid hormonal therapy (Optimal dosages and overdosages) as Pionnary Auto-immune Primary Hypothyroidism in Dakar [Senegal] gives us A Propose of Whitaker Syndrome Case Report and THYROID GLAND AND ITS PEPTIDES OR ACTUALITYOF GENERAL ENDOCRINOLOGY. Many peptides by their cell molecular metabolism in the thyroid gland are involved: mutations of TSH receptor is linked to hormone resistance with congenital hypothyroidism; a new oroxigenic peptide, Ghrelin is widespread in endocrine tissues; tachykinine is another novel peptide with endocrine paracrine effect. PTTG and FGF-2 are prognostic markers of differentiated cancers; CRIF1 is a novel protein of nucleus interacting with Gadd45 and could negatively regulate cycle cell progression and cell growth; mutations of RET protooncogene is now the best CMT biomarker in the place of calcitonin in addition with CGRP $\propto$, CGRP $\beta$ and Amylin; regulating proteins of CAMP, protein G, Gi alpha 1, MAL proteolipid are identified near immunologic antigens involved in Grave's disease, autoimmune polyendocrinopathies. These peptides by their diversity of function support the concept of general endocrinology equivalent of medical sciences. Bastenie P. A. classification is a bio-clinical semeiology that could be reviewed by doing the integration of obesity as the incipient stage of epigenetic thyroid turnover of deiodinase realizing an inactive TSH. Thus primary hypothyroidism in an historical-technically point of view can recognize since Bastenie: -1 Atrophic thyroid myxedema with: low T4 and low T3 and High TSH and TRH positive. -2 Mild hypothyroidism where only TSH is High and TRH Test positive. -3 Infra-clinic hypothyroidism where only TRH Test is positive. -4 Compensated thyroiditis where only auto-antibodies are positive. -5 Common obesity where deiodinase turnover is only disturbed. Iodine regulates nutritional metabolism probably via the microbiome. Thyro-diabetes has concerned clinicians. Endocrine disruptors have come to recall us if necessary that thyroid gland is a gate keeper of the environment which in our approach is the testimony of primordial role of mineral iodine in the majority of living beings. Here are the perspectives of General Practitioner of Endocrine Diseases and Clinical Medicine Department.
\end{abstract}

Keywords: Multicentric Epidemiology, Primary Hypothyroidism AutoImmunity, Diabetes, Africa Medical Sciences, Peptides Immunoradiometry, Thyreoliberine, Levothyroxine 


\section{Introduction}

We have reported a linked thyroiditis to renal multiple complications [1] encountered in our settlement as 1978 Intern of Medical Anthropology Applied to Development and Health [at pavilion Laveran of chair of clinical internal general medicine practitioner] and 1995 Senior Student for the Advancement of Science in Serving Science and Technology [at the new York academy of sciences in endocrinology and computer science] and encountered a second case as retired in which was showed renal glomerular amyloidosis with tubule-interstitial impact.

Those facts decided us to review the literature as a commentary our main work of student for the Advancement of Science in a Multicentric Hospital Clinical Forms of SubSaharan Auto-immune Peripheral Hypothyroidism with the optimal dosages of the treatment of primary hypothyroidism. [1].

\section{Material \& Methods}

Setting: clinical medicine division of Internal Medicine [Dakar University Faculty of medicine pharmacy and dentistry] Pr. Dean Marc Henri Christian Sankale Corresponding National Member of Academie Nationale de Medecine de Paris (1978).

Internship visiting consultation: bedside daily examination [pavilion Laennec Sector] Pr. Yacouba Issagha Toure Nephrology Necker-Enfants-Malades corresponding affiliated. (1982)

Residency tele-service: http://www.auf.org Pr. Jean Lubetzki [medical sciences of Lariboisiere Hospital] (1984).

Master of sciences: http://www.salk.edu Pr. Roger Charles Louis Guillemin Chairman in endocrinology (2000).

Post doc fellow: college-de-france.fr Experimental Medicine Pr. Monique Vincens Cyto-histo-anatomopathology (2019).

We have reported a linked thyroiditis to renal multiple complications [1] encountered in our settlement as 1978 Intern of Medical Anthropology Applied to Development and Health [at pavilion Laveran of chair of clinical internal general medicine practitioner] and 1995 Senior Student for the Advancement of Science in Serving Science and Technology [at the new York academy of sciences in endocrinology and computer science] and encountered a second case as retired Senior in which was showed renal glomerular amyloidosis with tubule-interstitial impact.

\section{Results}

\subsection{Case Report Data}

M. S. T., 37 years old, residing in Cap-Vert Region, was hospitalized in March, 221983 for effort dyspnea, and generalized edemas.

Aspect and disproportionated age and height of the patient, pulse at 39 , temperature at 36 Celsius degree, just tolerable psychism associated with disharmonized dwarfism had oriented us towards a thyroid disease. Clinical examination and laboratory investigation had evidenced a global cardiac insufficiency [GCI], with non-visible neither palpable cardiac choc point, cardiac dullness enlarged area, deafer heart noises but regular rhythm, big cardiac liver with jugular-liver reflux, a low voltage generalized to all electro-cardio-graphic examination areas and enlarged heart as a "theiere" at the radiography. Here was a pericardia effusion with global cardiac decompensation. The skin was covered with multiple xanthomas. The patient also hold hernia on under umbilicus white line. After biological confirmation of hypothyroidism clinically suspected opotherapy was conducted progressively. After treatment of a month duration, we assisted to a quick cardiac well-being of the GCI and the disappearance of cutaneous xanthomas. Radiologic status of the patient evidenced hypothyroid osteopathy, multiple stones of urinary tracts clinically mild and nephrocalcinosis.

Research of aetiologia of opacity radiology of multiple stones revealed to us existence of metabolic acidosis with normal kidney function, without anion ionic gap but hypercalcemia. Laboratory findings are on Table 1.

A persisting pain of right hypochondria in this context had shown us possibility of gallbladder lithiasis that was confirmed by echography and cholecystography.

Two surgical acts successively had permitted to extract ureteral calcic stones [five on the left, two on the right] and the cholesterol gallbladder stone, and to do the cure of umbilicus hernia.

During the surgical act, the surgeon discovered fortuity a "kissing ulcer" of duodenal bulb for which truncular vagotomy was done.

Surgery acts were without complication in the immediate evolution and the patient had a well-being in this time under opotherapy and discontinued alcalinisation.

\subsection{Laboratory Investigation}

Table 1. Laboratory Findings.

\begin{tabular}{llllll}
\hline & Before treatment & After 3 months of opotherapy & $\mathbf{1 9 8 4}$ & $\mathbf{1 9 8 5}$ & $\mathbf{1 9 8 6}$ \\
\hline Calcemia & $114 \mathrm{mg} / 1$ & $95 \mathrm{mg} / 1$ & $109 \mathrm{mg} / 1$ & $105 \mathrm{mg} / 1$ & $102 \mathrm{mg} / 1$ \\
Calciuria & $107 \mathrm{mg} / 1$ & $100 \mathrm{mg} / 1$ & - & - & - \\
Auto-antibodies anti-thyroglobulin & Positive at $1 / 80$ & - & - & - & - \\
Auto-antibodies anti -microsomal & Positive at $1 / 100$ & - & - & - & - \\
\hline
\end{tabular}




\begin{tabular}{|c|c|c|c|c|c|}
\hline & Before treatment & After 3 months of opotherapy & 1984 & 1985 & 1986 \\
\hline $17 \mathrm{OH} \mathrm{CS}$ & $2,95 \mathrm{mg} / 24 \mathrm{~h}(\mathrm{~N}=3-8)$ & - & - & - & - \\
\hline 17 ketos & $3,85 \mathrm{mg} / 24 \mathrm{~h}(\mathrm{~N}=10-30)$ & - & - & - & - \\
\hline Glycemia & $0,80 \mathrm{~g} / 1$ & $0,90 \mathrm{~g} / 1$ & $0,70 \mathrm{~g} / \mathrm{l}$ & $0,80 \mathrm{~g} / \mathrm{l}$ & - \\
\hline Creatininemia & $10 \mathrm{mg} / \mathrm{l}$ & $12 \mathrm{mg} / \mathrm{l}$ & $10 \mathrm{mg} / \mathrm{l}$ & $15 \mathrm{mg} / \mathrm{l}$ & $13,86 \mathrm{mg} / \mathrm{l}$ \\
\hline Alcaline Reserve & $7,9 \mathrm{mEq}$ & $9,5 \mathrm{mEq}$ & $2,16 \mathrm{mEq}$ & $?$ & 27 \\
\hline Fixation $/ 1321$ & Patent hypo fixation & - & - & - & - \\
\hline PTH & $23 \mathrm{mg} / 1(\mathrm{~N}=20-45)$ & - & - & - & - \\
\hline $25 \mathrm{OHD}$ & $14,8 \mathrm{ng} / 1(\mathrm{~N}=5-30)$ & - & - & - & - \\
\hline Achill gram reflex & $310 \mathrm{~ms}$ & - & - & - & - \\
\hline Echography & $\begin{array}{l}\text { Thyroid in place. } \\
\text { Gallbladder lithiasis }\end{array}$ & - & - & - & - \\
\hline Total Lipids & $10 \mathrm{~g} / 1$ & $7 \mathrm{~g} / 1$ & $8 \mathrm{~g} / 1$ & - & - \\
\hline Cholesterol & $2,60 \mathrm{~g} / 1$ & $1,70 \mathrm{~g} / 1$ & $1,65 \mathrm{~g} / 1$ & - & - \\
\hline $\mathrm{T}_{3}$ test & Normal & - & - & - & - \\
\hline TSH & $189 \mathrm{mU} / 1$ & - & - & - & - \\
\hline Total Thyroxine & $\mathrm{T} 19 \mathrm{nmol} / \mathrm{l}(\mathrm{N}=80-140)$ & \multirow{2}{*}{ Normal Values } & - & - & - \\
\hline Free T4 ITL & $3 \mu \mathrm{g} / \mathrm{dl}(\mathrm{N}=14-45)$ & & - & - & - \\
\hline
\end{tabular}

Anatomic-histological biopsy in a same patient reordered: Amyloidosis of the kidney glomerular and tubule-interstitial impact. [2018]

\section{Discussion}

Related since 1895 by Exald quoted by Ducros, this myxedema and diabetes association appeared in long time as scarce... Since refinement recently of thyroid essays means, hypothyroidism epidemiology has been marked by growing prevalence mainly in female sex and elderly. Elsewhere, description has been scarcely. Thus, Trowell outside one case, reported no any case before 1960 in Africa. We reported one potential glucose tolerance abnormality in a case. The diabetes of type II was noninsulin dependent and of plethoric type in 3 cases. In 2 cases diabetes was after and revealed by cardinal signs of polyuria-polydipsia type. Reversely, in the late case diabetes was anterior for 5 years to hypothyroidism; it was screened systematically at the surge of an abscess of the groin in a subject genetically exposed and just presently without any hypothyroidism manifestation.

Obesiologic note: Authentic dissertations have traced the pathogenesis link of X polymetabolic syndrome: Ord and Gull [late 1800], Jean Vague [1945] "apple" or «pear" obesity, the research of Hans Selye [towards 1960], concepts of Neufeld, insulin-resistance of Reaven [towards 1980], Samuel Refetoff description of thyroid hormone resistance syndrome and finally D. J. P. Barker, towards 1992 reported fetal and infant origins of adult diseases by trans generationally epigenesis; elsewhere graduated by Bastenie P. A., towards 1937 and Reginal Hall and David Ormston in early 1970. Our group in internship report at Semaine des Hopitaux de Paris has described auto-immune thyroiditis [2-10] with polyvisceral complications [hypercalcemic lithiasis with normal PTH, kissing ulcer and cardiomyopathic anasarca]. In 24 cases of primary hypothyroidism in our inaugural dissertation of 1984, march 28, with those of Joslin's 1985 textbook we apologize the large spectrum of endocrine diseases in the association of endocrinopathies and diabetes mellitus [11-20]. In fact evidence through 202 cases of maternal diabetes of a probable intra-uterine factor in non insulin dependent diabetes named type II in one of our dissertation has allowed us to argument in the hypothesis of D. J. P. Barker.

Insulin like growth factors nutritional regulation: IGFs I and II are structurally linked to insulin hormone. These IGFs are of 7.5 kilo daltons comprised between 70 to 67 residual amino-acid for respectively four domains designated A, B, C, and $\mathrm{D}$ as identified. Nutrition is the main regulator of circulating human IGFI. Energy and proteins are very important in the regulation. The liver by its receptors in GH plays a role depending on the severity of nutritional gap. Decline of IGF-I gene expression is mainly caused by nutritional defect and less importantly by nutritionally inducted hormonal changes [insulin and T3]. Two recent datas demonstrate that nutrients can also regulate biological action of IGF-I directly or indirectly through proteins linked to IGF-I [IGF Bps].

Sounds about X polymetabolic syndrome [a propose of an potentially abnormal gestational tolerance of glucose and primary hypothyroidism in a French citizen living in Dakar] call us to the suiting ideas:

In Clinical Medicine in Dakar, iodine nutrition is distinguished in four cases by diabetes: calcic with a case at Semaine des Hopitaux de Paris in 1988 [21-30] and mellitus in three cases in Black Senegalese Women in the inaugural dissertation of Marie Safetou Ka-Cisse in 1986.

\section{Conclusion}

Iodine regulates nutritional metabolism probably via the microbiome. Thyro-diabetes has concerned clinicians. Endocrine disruptors have come to recall us if necessary that thyroid gland is a gate keeper of the environment which in 
our approach is the testimony of primordial role of mineral iodine in the majority of living beings.

General conclusion: Bastenie P. A. classification is a bioclinical semeiology that could be reviewed by doing the integration of obesity as the incipient stage of epigenetic thyroid turnover of deiodinase realizing an inactive TSH [3140]. Thus, primary hypothyroidism in an historicaltechnically point of view can recognize since Bastenie:

1. Atrophic thyroid myxedema with low T4 and low T3 and High TSH and TRH positive.

2. Mild hypothyroidism where only TSH is High and TRH Test positive

3. Infra-clinic hypothyroidism where only TRH Test is positive.

4. Compensated thyroiditis where only auto-antibodies are positive.

5. Common obesity where deiodinase turnover is only disturbed.

Here are the perspectives of General Practitioner of Endocrine Diseases and Clinical Medicine Department [1-42].

Since the introduction of third generation of the TSH assay methods, TRH test remains only essential for limited domains. But for some authors, application of immunoradiometric assays combined with TRH test have not sufficiently evaluated as remarked by some authors. Thyrotrophic cell has a potent desiodase and active in normal subject explaining the strong correlation between T4 and TSH. Interindividual variability of the activity of desiodase enzyme is very possible because of genetic polymorphism. We have studied prospectively and determined in and homogenous patients population with treated primary hypothyroidism, a real overdosage by an abolished first generation immunoradiometric TSH to TRH and given optimal dosage of levothyroxine during substitutive thyroid hormonotherapy.

Our criterias for TSH reponse to TRH had for lower limite a delta TSH of $4 \mathrm{UI} / \mathrm{ml}$, this is higher than lower level of 1 $\mathrm{UI} / \mathrm{ml}$ proposed by some authors. TRH tests as other dynamic assays of anterior pituitary are useful to amplify subtle abnormalities. A defect in reponse to hypothalamic hormone can be caused by absence or dysfunction of pituitary cells or elevated negative feedback by peripheral hormones. An example of this situation is lost of response of TSH to TRH in thyrotoxicosis. Finally, in incipiens primary hypothyrodisme or thyrotoxicosis TRH test remains particularly indicated even in presence of immunoradiometric TSH assay.

Body weight $/ \mathrm{kg}$ dosage in our patients is between those proposed $(1.72+036 \mathrm{microg} / \mathrm{kg} / \mathrm{d})$ and $(2.08+0.58$ microg $/ \mathrm{kg} / \mathrm{d})$; the 2 series had a equivalent mean age with ours. But patients older have received identical body weight dosage $(1.86+0.08 \mathrm{microg} / \mathrm{kg} / \mathrm{d})$ in patients 60 years older; other authors haved proposed a lower dosage (1.60 microg $/ \mathrm{kg} / \mathrm{j}$ ) for a mean age of 68 years.

The body surface $/ \mathrm{m}^{2}$ dosage allowing an euthyroidy is $67.3+14.1 \mathrm{microg} / \mathrm{m}^{2} / \mathrm{d}$ in a serie while that its raises to $72.75+7.5 \mathrm{microg} / \mathrm{m}^{2}$ in our serie; the mean age being respectively $54+11$ et $58+15$ ans. In our patients treated with levothyroxine, we have observed a daily $/ \mathrm{m}^{2}$ dosage more correlated with delta TSH. This result is in conformation with those of other authors. We have remarked that this discrimination is less important in the group treated by levothyroxine and triiodothyronine

We have not observed modification in cholesterolemia during comparison of patients with delta TSH less than 4 micro UI/ml with those with more than 4 micro UI/ml. No evident relation was observed when delta TSH was lower than $4 \mathrm{micro} \mathrm{UI} / \mathrm{ml}$. This fact signifies that modifications leading to decrease delta TSH do not disturb cholesterolemia.

Even if immunoenzymatic technical essay of first generation was use in our study, our results are important [41; 42]. Because the population studied of 52 patients with 92 TRH tests under levothyroxine and association levothyroxine and triiodothyronine has allowed to evaluate an optimal hormonal control.

\section{References}

[1] Y. I. TOURE, E. H. SIDIBE, M. L. DIOUF, B. A. DIAGNE, B. DIOP. (1988) Hypercalcémie, acidose tubulaire rénale, ulcère du bulbe duodénal et lithiases vésiculo-urinaires chez un hypothyroïdien. Sem. Hôp. Paris, 64, 2: 125-127.

[2] Linda Humbert, Marjorie Cornu, Emmanuelle Proust-Lemoine, Jagadeesh Bayry, Jean-Louis Wemeau, Marie-Christine Vantyghem, Boualem Sendid (2018) Chronic Mucocutaneous Candidiasis in Autoimmune Polyendocrine Syndrome Type 1 Front Immunol.; 9: 2570.

[3] Eystein S. Husebye, Mark S. Anderson, Olle Kämpe (2018) Autoimmune Polyendocrine Syndromes N Engl J Med.; 378 (12): 1132-1141.

[4] Hargovind L Trivedi, Umang G Thakkar, Aruna V Vanikar, Shruti D Dave (2011) Treatment of polyglandular autoimmune syndrome type 3 using co-transplantation of insulin-secreting mesenchymal stem cells and haematopoietic stem cells BMJ Case Rep.; 2011: bcr0720114436.

[5] C Betterle, F Lazzarotto, F Presotto (2004) Autoimmune polyglandular syndrome Type 2: the tip of an iceberg? Clin Exp Immunol.; 137 (2): 225-233.

[6] Øyvind Bruserud, Bergithe E. Oftedal, Nils Landegren, Martina M. Erichsen, Eirik Bratland, Kari Lima, Anders P. Jørgensen, Anne G. Myhre, Johan Svartberg, Kristian J. Fougner, Åsne Bakke, Bjørn G. Nedrebø, Bjarne Mella, Lars Breivik, Marte K. Viken, Per M. Knappskog, Mihaela C. Marthinussen, Kristian Løvås, Olle Kämpe, Anette B. Wolff, Eystein S. Husebye (2016) A Longitudinal Follow-up of Autoimmune Polyendocrine Syndrome Type $1 \mathrm{~J}$ Clin Endocrinol Metab.; 101 (8): 2975-2983.

[7] M. I. Drury, Deborah M. Keelan, F. J. Timoney, W. J. Irvine (1970) Juvenile familial endocrinopathy Clin Exp Immunol.; 7 (1): $125-132$.

[8] W. J. Irvine, A. G. Stewart, Laura Scarth (1967) A clinical and immunological study of adrenocortical insufficiency (Addison's disease) Clin Exp Immunol.; 2 (1): 31-70. 
[9] Leonard Wartofsky, Peter Smyth, Josef Köhrle, Ryszard Anielski, Marian Slowiaczek, Pawel Orlicki, Rafal Czepczynski, Jacek Daroszewski, Alicja HubalewskaDydejczyk, Aldona Kowalska, Maria Kurowska, Joanna Malicka, Anna Oszywa-Chabros, Agnieszka Zwolak, Jerzy S. Tarach, Krzysztof C. Lewandowski, Andrzej Lewinski, Anna Szeliga, Adam Czyzyk, Przemyslaw Niedzielski, Miroslaw Mleczek, Adam Maciejewski, Anna Oczkowska, Jolanta Dorszewska, Katarzyna Lacka, Jerzy S. Tarach, Elzbieta Andrysiak-Mamos, Elzbieta Sowinska-Przepiera, Ewa Zochowska, Bartosz Kiedrowicz, Agnieszka KazmierczykPuchalska, Anhelli Syrenicz, Katarzyna D. Arczewska, Joanna Drozdowska, Wanda Krasuska, Anna Stachurska, Grazyna Hoser, Miroslaw Kiedrowski, Tomasz Stepien, Hilde Nilsen, Barbara Czarnocka, Karolina H. Czarnecka, Michal Kusinski, Agnieszka Nadel, Justyna Kiszalkiewicz, Daria Domanska, Monika Migdalska-Sek, Dorota Pastuszak-Lewandoska, Ewa Nawrot, Krzysztof Kuzdak, Ewa Brzezianska-Lasota, Barbara Czarnocka, Anna Maria Dabrowska, Jolanta Kijek, Jerzy S. Tarach, Anna Torun-Jurkowska, Beata Chrapko, Anna Maria Dabrowska, Jerzy S. Tarach, Jolanta Kijek, Helena Jastrzebska, Magdalena Kochman, Ewa Szczepanska, Joanna Zgliczynska-Widlak, Agnieszka Samsel, Wojciech Zgliczynski, Roman Junik, Dariusz Kajdaniuk, Grzegorz Kaminski, Grzegorz Kaminski, Krzysztof Giejda, Malgorzata Karbownik-Lewinska, Magdalena Marcinkowska, Jan Stepniak, Andrzej Lewinski, Monika Koziolek, Anna Sieradzka, Magdalena Lewandowska, Maria Stepaniuk, Bartosz Kiedrowicz, Julita Duda, Elzbieta Andrysiak-Mamos, Anhelli Syrenicz, Monika Koziolek, Anna Sieradzka, Ewa Wentland-Kotwicka, Bartosz Kiedrowicz, Milosz Parczewski, Maria Stepaniuk, Agnieszka Binczak-Kuleta, Andrzej Ciechanowicz, Elzbieta Andrysiak-Mamos, Anhelli Syrenicz, Maria Kurowska, Joanna Malicka, Piotr Denew, Agnieszka Zwolak, Monika Lenart-Lipinska, Jerzy S. Tarach, Katarzyna Lacka, Dagny Lapinska, Kosma Wolinski, Magdalena Matysiak-Grzes, Aleksandra Klimowicz, Edyta Gurgul, Rafal Czepczynski, Maria Gryczynska, Marek Ruchala, Hanna Mikos, Marcin Mikos, Barbara Rabska-Pietrzak, Marek Niedziela, Marek Ruchala, Ewelina Szczepanek-Parulska, Magdalena Rudzinska, Joanna Ledwon, Kamila Karpinska, Maria Macios, Justyna Sikorska, Barbara Czarnocka, Malgorzata Ruminska, Ewelina Witkowska-Sedek, Beata Pyrzak, Nadia Sawicka-Gutaj, Anna Sieradzka, Monika Koziołek, Magdalena Lewandowska, Ewa WentlandKotwicka, Marcin Machaj, Lilianna Osowicz-Korolonek, Jakub Pobłocki, Anhelli Syrenicz, Jerzy Sowinski, Nadia Sawicka-Gutaj, Paulina Ziolkowska, Marek Ruchala, Ewelina Szczepanek-Parulska, Bartlomiej Budny, Marek Ruchala, Malgorzata Trofimiuk-Muldner, Katarzyna Ziemnicka, Dorota Zozulinska-Ziolkiewicz (2016) Abstracts and short papers from the 5th Congress of the Polish Thyroid Association, Poznan, 3-5 September, 2015: Poznan, Poland. 3-5 September 2015 Thyroid Res.; 9 (Suppl 1): 6.

[10] Sakeen W. Kashem, Bryce A. Binstadt (2017) Pathogenic and Protective Autoantibodies in Autoimmune Polyendocrinopathy-Candidiasis-Ectodermal Dystrophy (APECED) Antibodies (Basel); 6 (1): 1.

[11] R. Duclaux-Loras, F. Charbit-Henrion, B. Neven, J. Nowak, S. Collardeau-Frachon, C. Malcus, P. F. Ray, D. Moshous, J. Beltrand, O. Goulet, N. Cerf-Bensussan, A. Lachaux, F. Rieux-Laucat, F. M. Ruemmele (2018) Clinical Heterogeneity of Immune Dysregulation, Polyendocrinopathy, Enteropathy, X-Linked Syndrome: A French Multicenter Retrospective Study Clin Transl Gastroenterol.; 9 (10): 201.

[12] Carmine Siniscalchi, Valentina Moretti, Simona Cataldo,
Anna Rocci, Manuela Basaglia, Maria Ilaria Tassoni, Roberto Quintavalla, Carmine Siniscalchi, Valentina Moretti, Simona Cataldo, Anna Rocci, Manuela Basaglia, Maria Ilaria Tassoni, Roberto Quintavalla (2017) The Schmidt syndrome Acta Biomed.; 88 (4): 499-501.

[13] Oleksander Prylutskyi, Olga Prylutska, Anatoliy Degonskyi, Kseniia Tkachenko (2016) A Case of Autoimmune Polyglandular Syndrome. ype 2 Associated with Atypical Form of Scleromyxedema Ethiop J Health Sci.; 26 (5): 503-507.

[14] Gulbu Uzel, Elizabeth P. Sampaio, Monica G. Lawrence, Amy P. Hsu, Mary Hackett, Morna J. Dorsey, Richard J. Noel, James W. Verbsky, Alexandra F. Freeman, Erin Janssen, Francisco A. Bonilla, Joseph Pechacek, Prabha Chandrasekaran, Sarah K. Browne, Anahita Agharahimi, Ahmed M. Gharib, Sara C. Mannurita, Jae Joon Yim, Eleonora Gambineri, Troy Torgerson, Dat Q. Tran, Joshua D. Milner, Steven M. Holland (2013) Dominant gain-of-function STAT1 mutations in FOXP3WT IPEX-like Syndrome J Allergy Clin Immunol.; 131 (6): 1611-1623.e3.

[15] M Hong, K R Ryan, P D Arkwright, A R Gennery, C Costigan, M Dominguez, D W Denning, V McConnell, A J Cant, M Abinun, G P Spickett, D C Swan, C S Gillespie, D A Young, D Lilic (2009) Pattern recognition receptor expression is not impaired in patients with chronic mucocutanous candidiasis with or without autoimmune polyendocrinopathy candidiasis ectodermal dystrophy Clin Exp Immunol.; 156 (1): 40-51.

[16] T. Petteri Arstila, Hanna Jarva \{2013) Human APECED; a Sick Thymus Syndrome? Front Immunol.; 4: 313.

[17] Shrinivas Bishu, Violeta Arsenescu, Eun Y Lee, H David Vargas, Willem JS de Villiers, Razvan Arsenescu (2011) Autoimmune enteropathy with a CD8+ CD7- T-cell small bowel intraepithelial lymphocytosis: case report and literature review BMC Gastroenterol.; 11: 131.

[18] Dong Li, Elizabeth A. Streeten, Alice Chan, Wint Lwin, Lifeng Tian, Renata Pellegrino da Silva, Cecilia E. Kim, Mark S. Anderson, Hakon Hakonarson, Michael A. Levine (2017) Exome Sequencing Reveals Mutations in AIRE as a Cause of Isolated Hypoparathyroidism J Clin Endocrinol Metab.; 102 (5): 1726-1733.

[19] D C Aron, J B Tyrrell, C B Wilson (1995\} Pituitary tumors. Current concepts in diagnosis and management. West J Med.; 162 (4): 340-352.

[20] K R Ryan, M Hong, P D Arkwright, A R Gennery, C Costigan, M Dominguez, D Denning, V McConnell, A J Cant, M Abinun, G P Spickett, D Lilic (2008) Impaired dendritic cell maturation and cytokine production in patients with chronic mucocutanous candidiasis with or without APECED Clin Exp Immunol.; 154 (3): 406-414.

[21] Omar Bjanid, Piotr Adamczyk, Małgorzata Stojewska, Dagmara Roszkowska-Bjanid, Magdalena PaszynaGrześkowiak, Agnieszka Jędzura, Joanna Oświęcimska, Katarzyna Ziora, Aurelia Morawiec-Knysak, Maria Szczepańska (2017) Rare case of nephrocalcinosis in a 14year-old girl: Answers Pediatr Nephrol.; 32 (4): 609-613.

[22] Preetesh Jain, Luis Baez-Vallecillo, Yang O Huh, Ohad Benjamini, Lynne Abruzzo, Susan O'Brien, Naveen Pemmaraju, Michael Keating, Robert F. Gagel, Zeev Estrov (2014) Atypical chronic lymphocytic leukemia (CLL) with polyglandular autoimmune endocrinopathy (PGA) type II - a complex profile Leuk Lymphoma.; 55 (4): 944-946. 
[23] James W. Verbsky, Talal A. Chatila (2013) Immune Dysregulation, Polyendocrinopathy, Enteropathy, X-linked (IPEX) and IPEX-Related Disorders: an Evolving Web of Heritable Autoimmune Diseases Curr Opin Pediatr.; 25 (6): 708-714.

[24] ESP Abstracts 2013 Virchows Arch.; 463 (2): 101-352.

[25] R Wildin, S Smyk-Pearson, A Filipovich (2002) Clinical and molecular features of the immunodysregulation, polyendocrinopathy, enteropathy, X linked (IPEX) syndrome J Med Genet.; 39 (8): 537-545.

[26] Omar K. Alkhairy, Nima Rezaei, Robert R. Graham, Hassan Abolhassani, Stephan Borte, Kjell Hultenby, Chenglin Wu, Asghar Aghamohammadi, David A. Williams, Timothy W. Behrens, Lennart Hammarström, Qiang PanHammarström\{2015) RAC2 Loss-of-function Mutation in Two Siblings with Characteristics of Common Variable Immunodeficiency J Allergy Clin Immunol.; 135 (5): 13801384.e5.

[27] E. Helen Kemp, Nikos G. Gavalas, Kai J. E. Krohn, Edward M. Brown, Philip F. Watson, Anthony P. Weetman (2009) Activating Autoantibodies against the Calcium-Sensing Receptor Detected in Two Patients with Autoimmune Polyendocrine Syndrome Type 1 J Clin Endocrinol Metab.; 94 (12): 4749-4756.

[28] Pierre Ronco, Hanna Debiec Pathophysiological lessons from rare associations of immunological disorders Pediatr Nephrol.; 24 (1): $3-8$.

[29] Hans J. J. van der Vliet, Edward E. Nieuwenhuis (2007) IPEX as a Result of Mutations in FOXP3 Clin Dev Immunol.; 2007: 89017.

[30] G Brancatelli, M Galia, G Sparacia, S Cusma, R Lagalla (2000) Left kidney mass in a 45 year old woman Postgrad Med J.; 76 (901): 722-733.

[31] F Rorsman, E S Husebye, O Winqvist, E Björk, F A Karlsson, O Kämpe (1995) Aromatic-L-amino-acid decarboxylase, a pyridoxal phosphate-dependent enzyme, is a beta-cell autoantigen. Proc Natl Acad Sci U S A. 1995; 92 (19): 86268629 .
[32] S Singh, A Lone, B Khan, A Khan, M Wani (2000) Shortness of breath and diffuse chest pain Postgrad Med J.; 76 (901): 721-731.

[33] Alice Poisson, Alain Nicolas, Pierre Cochat, Damien Sanlaville, Caroline Rigard, Hélène de Leersnyder, Patricia Franco, Vincent Des Portes, Patrick Edery, Caroline Demily (2015) Behavioral disturbance and treatment strategies in Smith-Magenis syndrome Orphanet J Rare Dis. 2015; 10: 111.

[34] The Ulster Medical Journal index: volumes 1-64. (1998) Ulster Med J.; 67 (Suppl 2): 1-60.

[35] D C Dorman, S L Allen, J Z Byczkowski, L Claudio, J E Fisher, Jr, J W Fisher, G J Harry, A A Li, S L Makris, S Padilla, L G Sultatos, B E Mileson (2001) Methods to identify and characterize developmental neurotoxicity for human health risk assessment. III: pharmacokinetic and pharmacodynamic considerations. Environ Health Perspect.; 109 (Suppl 1): 101-111.

[36] Abstracts from Purines 2014, an International Conference on Nucleotides, Nucleosides and Nucleobases, held in Bonn, Germany, from July 23-27, 2014 Purinergic Signal.; 10 (4): 657-854.

[37] J. F. Boyd, A. M. MacDonald (1960) Adrenal Cortical Hypoplasia in Siblings Arch Dis Child.; 35 (184): 561-568.

[38] M J Kupersmith, R M Burde, F A Warren, T G Klingele, L P Frohman, H Mitnick (1988) Autoimmune optic neuropathy: evaluation and treatment. J Neurol Neurosurg Psychiatry.; 51 (11): 1381-1386. J Neurol Neurosurg Psychiatry.; 52 (5): 692.

[39] N Maskell, R Butland (2003) BTS guidelines for the investigation of a unilateral pleural effusion in adults Thorax.; 58 (Suppl 2): ii8-ii17.

[40] Carl E. Allen, Stephan Ladisch, Kenneth L. McClain \{2015) How I treat Langerhans cell histiocytosis Blood.; 126 (1): 2635 .

[41] Ilias Attaye, Merel van Andel, Albertus Jozef Kooter (2018) More, less or both? BMJ Case Rep.; 2018: bcr2017222355.

[42] M. Goust, A. Castaigne, R. Moulias (1974\} Delayed hypersensitivity to muscle and thymus in myasthenia gravis and polymyositis Clin Exp Immunol.; 18 (1): 39-47. 